\title{
The role of innovations in the development of agriculture in Russia
}

\author{
Evgeniy Kharitonov ${ }^{1, *}$, Karina Krikun ${ }^{1}$, and Alexander Nesmyslenov ${ }^{2}$ \\ ${ }^{1}$ Federal State Budgetary Educational Institution of Higher Education "Kuban State Agrarian \\ University named after I.T. Trubilina", Kalinina St., 13, 350044 Krasnodar, Russia \\ ${ }^{2}$ Federal State Budgetary Scientific Institution (FSBSI) "Povolzhskiy Research Institute of Economics \\ of the Organization of Agroindustrial Complex", Shekhurdina st. 12, 410010 Saratov, Russia
}

\begin{abstract}
This article is intended to substantiate the role of innovations in the development of agriculture in Russia. The authors of the article focused on identifying the importance of innovative techniques and technologies in the modern development of the agricultural industry. The current directions of innovative developments in the agricultural sector in Russia have been identified and investigated. The conditions for achieving effective implementation of digital land use projects are presented; "Smart field"; "Smart garden; Smart farm. The experience and level of development of innovative techniques and technologies in foreign countries are considered. An up-to-date list of both Russian and foreign manufacturers of innovative developments, the buyers of which are domestic agricultural organizations, is presented. The factors that hinder the active implementation of innovations in the activities of agricultural entities in Russia have been identified. A diagram of the relationship between the components of the process of creating and applying innovative technologies has been developed. Also the author's schematic position of the role and place of innovations in the process of creating and applying innovative technologies is presented. As a result of the research, there were given recommendations for eliminating the identified problems in the field of introducing innovative techniques and technologies in agricultural production.
\end{abstract}

\section{Introduction}

The use of innovative digital technologies for the agricultural sector is necessary to increase the efficiency of the functioning of agricultural production entities, especially private forms of ownership. The use of innovative digital technologies contributes to a radical change in the quality of manufactured products, and also makes it possible to correctly predict the level of marketability of products in a rapidly transforming economy.

The practice of foreign agricultural manufactures, as well as the experience of Russian agricultural entities, show that the use of innovative technologies in the production process makes it possible to determine the optimal combination of soil-agrotechnical and

\footnotetext{
${ }^{*}$ Corresponding author: istor-polit@kubsau.ru
} 
organizational-territorial conditions that contribute to significantly increase yields, productivity, labor productivity throughout the entire period of agricultural production, minimize direct production costs, preserve soil fertility and positively influence environmental safety.

At the present time, the research institute of the Russian Agricultural Academy, together with the Ministry of Agriculture of Russia and agricultural universities of the country, are developing highly productive breeds of animals, birds, fish, as well as high-yielding varieties and hybrids of agricultural crops. It should be noted that foreign scientific structures have the most successful experience in creating resource-saving and environmentally friendly equipment. So, in modern conditions, among Russian agricultural producers, there is a tendency to an increase in demand for the use of foreign innovative techniques and technologies.

Despite the positive effect of the use of innovative technologies, at present there remains an acute problem in their use among Russian agricultural entities. The main reason for this is the long-term ineffective investment climate, which was a typical source for the current period, of a low level of provision of agricultural entities with innovative equipment, techniques and technologies, which emphasizes the relevance of the scientific article.

\section{Materials and Methods}

The theoretical and methodological basis of our research is the scientific development of foreign and domestic scientists on the use of innovative techniques and technologies in agricultural production in the context of modern world politics.

The scientific article examines the experience of using innovation in agriculture, both foreign and domestic agricultural producers. In the scientific article, we used research methods: monographic, comparison, index, graphic, calculation and analytical techniques and other methods based on statistical data from 2017 to 2019.

\section{Results and Discussion}

The use of innovative techniques and technologies in agriculture is an innovative activity of an economic entity. Note that at the present time, innovative activity does not have the character of a one-time stage, especially for the agricultural sector, the specificity of this activity is in its cyclical nature. Carrying out innovative activities, the management of an agricultural organization should focus on the simplest innovations when choosing scientific developments for their introduction into the production process, in view of the fact that complicated innovations are often unfeasible and require scientific improvements, which leads to high financial costs and requires a long time for their effective use [4].

We emphasize that the use of innovative techniques and technologies plays an important role in the functioning of an agricultural organization. In research of Kovalchuk M. D. in the development of an integral model for assessing the economic efficiency of forms of ownership of agricultural entities, the "level of innovative development" indicator is 0.3 , which suggests that the author assesses the role of this indicator in the activities of an agricultural entity on $30 \%$ of the total number of recorded indicators, which is a fairly high proportion $[1,5-6]$.

The development of agriculture in Russia in recent years in the context of an embargo on the import of a number of products has identified some sectoral problems that need to be addressed, including through the introduction of innovations. The transition of agricultural production to the level of a high-tech industry is due to the relevance of ensuring the country's food security in the context of modern world politics. There is an urgent need to create a 
favorable innovation and investment climate for the introduction of innovative techniques and technologies in the agricultural sector to provide the Russian population with highquality and safe agricultural products.

The current level of innovative development of Russian agricultural organizations is of serious concern due to the lack of scientific and practical knowledge in the application of modern innovative agricultural technologies, difficulties in predicting the cost of agricultural products and the required number of innovative techniques and technologies for the effective operation of agricultural organizations [2-3]. At the present time, innovative developments in the agricultural sector in Russia are carried out in the following areas: innovations for the efficient production of agricultural products; innovations to improve the processes of public administration in the field of agriculture [7-8].

Innovation for efficient agricultural production focuses on:

- the formation and continuous replenishment of the information base on the areas of agricultural land, on sown areas by types and varieties of agricultural crops, yield, number and breeds of farm animals, the state of agricultural machinery and equipment;

- involvement of agricultural enterprises in resource-saving and environmentally friendly production;

- minimization of production costs of agricultural enterprises, optimization of land use, involvement of unused agricultural land in economic circulation;

- reduction of the share of material costs in the structure of the unit cost of agricultural products;

- reducing the labor intensity of agricultural production.

To this date, the following directions for the introduction of innovative techniques and technologies in the production of agricultural products have been identified in Russia: digital land use; smart field; smart garden; smart farm. Further, we will explore each of the above directions in more detail.

The main goal of digital farming is the creation and implementation of an innovative intelligent system for management, planning and use of agricultural land, the functionality of which is based on geoinformation technologies and the latest methods of computer modeling. The successful implementation of digital land use can only be recognized if:

- by 2024, the share of agricultural enterprises that have implemented an innovative system of planning and optimization of agricultural landscapes in their activities will be about $50 \%$;

- the level of profitability of production of agricultural enterprises will reach $50 \%$;

- by 2024, it is necessary to achieve complete digitization of the planning and cartographic material;

- by 2024 , it is necessary to carry out a complete delineation in the information bases of agricultural lands by forms of ownership.

The main goal of the "smart field" is to ensure stable growth of crop production through the introduction of innovative technologies for the collection, processing and use of information databases on the state of soils, plants and the environment. Successful implementation of the smart field can only be recognized if:

- an accuracy of $95 \%$ was achieved in assessing and predicting the yield of agricultural crops;

- an increase by $30 \%$ in yield has been achieved through the optimization of crop rotation, as well as the use of means to minimize the influence of factors that have a negative impact on the yield of agricultural crops;

- achieved minimization of direct production costs for the cultivation of agricultural crops in the amount of up to $20 \%$ by taking into account the technological properties and geographical location of agricultural land; 
- achieved 50\% introduction of a system of anti-erosion and environmental protection measures within the boundaries of fields among the total number of agricultural producers focused on the cultivation of agricultural crops;

- development and implementation of robotic technologies in field cultivation.

The main goal of the "smart garden" is the development and application of an intelligent technological system that automatically analyzes information about the state of the garden's agrobiocenosis, as well as effective management decisions and their implementation by robotic technical means. Successful implementation of a smart garden can only be recognized if:

- a complete digitization of the areas of garden perennial plantings and their introduction into a unified geographic information system has been achieved;

- the provision of more than $70 \%$ of garden organizations with information on the state of soils in areas of garden perennial plantations and the environment has been achieved;

- achieved $20 \%$ of field work robotization in a completely autonomous mode without human intervention;

- a 30\% increase in yield and an increase in the quality of fruit crops has been achieved through the implementation of innovative technological processes;

- achieved $40 \%$ minimization of production costs due to the optimal use of materials.

The main goal of the "smart farm" is the development and application of innovative technical and technological solutions for the creation of new generation farms based on intelligent digital technologies. According to forecasts, the development of the market for agricultural robots, the volume of the robotization market for dairy farms in 2023 will reach 504 billion rubles, currently - 120 billion rubles. Successful implementation of a smart farm can only be recognized if:

- a 70\% reduction in the incidence of mastitis in animals has been achieved;

$-40 \%$ profitability of production was achieved through robotization of the farm.

Note that at the present time, there is an active development of precision farming. Thus, such world leaders as the USA, Germany, Japan and China have reached a high level of development in this direction.

In the Russian Federation, in most cases, when implementing precision farming, innovative techniques and technologies of foreign manufacturers, for example, John Deere, are used. The reason for this is the low level of patent activity in the field of precision farming technologies in Russia relative to the world leaders.

Let us emphasize that for modern conditions, in the field of precision farming, rather active use of unmanned aerial vehicles is characteristic. Investigating the commodity structure of the robotechnics market for precision farming, it is worth noting that the production and sale of unmanned aerial vehicles makes up $20 \%$ of the total assortment. In Figure 1, we present the structure of the countries producing unmanned aerial vehicles. 


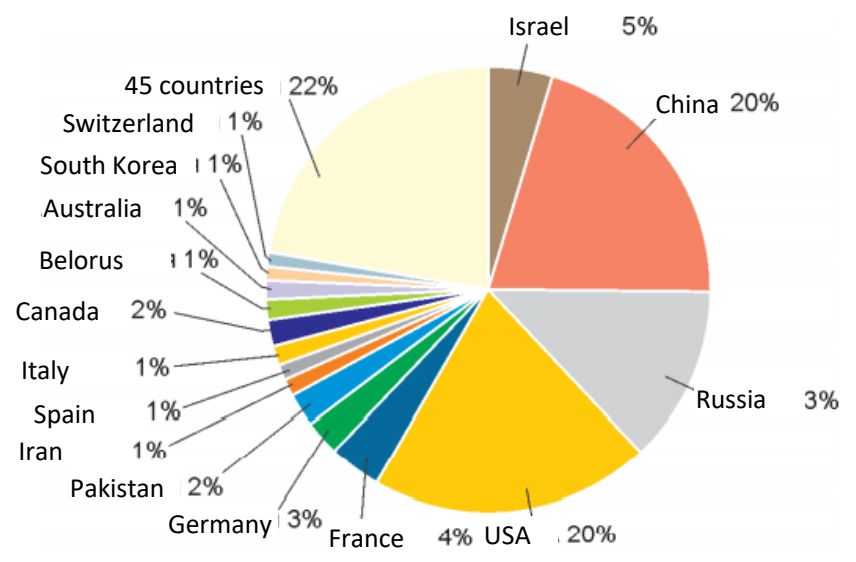

Fig. 1. Structure of countries producing unmanned aerial vehicles

So, according to Figure 1, the world leaders in the production of unmanned aerial vehicles are the United States and China with a total share of $40 \%$ of the total number of manufacturers, which produce more than 280 models annually. The Russian Federation is in third place with a $13 \%$ share and an annual production of 177 unmanned aerial vehicles.

At the present time, Russian manufacturers of innovative techniques and technologies for the crop production industry are:

- Cognitive Technologies, the main direction is the development and production of unmanned aerial vehicles. The key buyer is Special Economic Zone "Innopolis" ;

- Strizh-Telematica, the main direction is the development and production of detectors and sensors. The key buyer is "Valuikisakhar", California;

- RoboProb, the main direction is the development and production of land survey equipment. The key buyer is "White Bird";

- LLC "KSM-Intekh", the main direction is the development and production of precision farming systems. Key buyers are located in more than 50 regions of Russia.

Foreign manufacturers of innovative techniques and technologies for the Russian crop production industry are:

- Agroko, the main direction is the development and production of precision farming systems. The key buyer is Agroko (foreign software);

- Agrofirm "Progress", the main direction is the development and production of precision farming systems. The key buyer is Agrofirm "Progress" (foreign software).

In 2019, such innovative projects were announced:

- Project of a system for diagnosing the state of an animal during pasture keeping of cows. Initiator of the project is ZAO "Plant of electrical equipment";

- Project of a knowledge base in agriculture based on scientific publications and patents of Russia, USA,

Canada, Europe, China and other countries. Initiator of the project is Dataocean LLC;

- Project of a system for monitoring the health and reproduction of cattle. The initiator of the project is LLC "Perspektiva Group" with the support of the Altai State Agrarian University and the Moscow State Academy of Veterinary Medicine and Biotechnology named for K. I. Scriabin;

- Project of agrometeorological support for the activities of agricultural enterprises. Initiators of the project are LLC "CenterProgramSystem", LLC "Ilizium", Individual Undertaker Kurakov; 
- Project of a system for remote monitoring of agricultural machinery with obtaining economically important parameters and their use in management and economic accounting. The project initiator is LLC "Farvater".

At the present time, among domestic agricultural commodity producers, the innovative potential is used only by $4-5 \%$, while among economic entities in the US agricultural industry is by more than $50 \%$. Today, only $1-2 \%$ of the total number of innovative developments intended for agricultural production is used in Russia, while in the USA is about $70 \%$

Further, it is necessary to identify the factors that impede the active implementation of innovations in the activities of agricultural entities in Russia. They include:

- a shortage of highly qualified specialists with knowledge, skills, competence and experience that would allow the effective operation of innovative technologies in the production of agricultural products. The main reason for this problem is the high level of outflow of the able-bodied population from the village. The majority of active labor resources who have received education in the field of information and innovative technologies do not strive to implement their labor activity in the countryside;

- lack of effective training programs for training specialists in the use of modern innovative technologies for collecting and processing information on the state and use of agricultural lands;

- the high cost of foreign innovative developments, due to the close relationship with exchange rate changes in world currencies, as well as sanctions imposed by world leaders in relation to Russia and other trade restrictions within the framework of the low level of development of the Russian market for innovative technologies;

- lack of a regulatory framework and practice of interdepartmental interaction at the regional level;

- insufficient level of financing for the introduction of innovative techniques and technologies in most agricultural entities. Most of the agricultural producers, especially those in the "rural outback", have low solvency and for this reason they use outdated techniques and technologies in their production activities. In the current circumstances, due to the mechanisms of support for the subjects of the agricultural sector from the state in the conditions of available financing, in recent years, the volume of funds allocated for the purchase of modernized agricultural equipment at preferential prices has been significantly increased (in 2019, up to 5.2 billion rubles). However, the low economic potential of agricultural organizations leads to a minimization of the investment flow in fixed assets, savings on the purchase of equipment, which negatively affects the level of innovative activity of such economic entities.

To solve this problem, it is necessary to identify the relationship between the scientific potential and the direct application of innovative technology in production (Figure 2).

This diagram represents the connection between the 4 components of the process of creating and applying innovative technologies.

The scientific and educational structure is a supplier of ideas and results of scientific research, provides support and growth of the scientific level of production. The information structure is a database that contains all the information about the scientific achievements of the industry, as well as the cost of innovative technologies and how to use it.

State and municipal administration of the agro-industrial complex is a structure, the process of creating and applying innovative technologies, which performs the functions of financing both scientific research and their introduction into production, as well as monitoring the use of allocated funds.

The production structure is a unit of the process of creating and applying innovative technologies, which implements the request for innovation, as well as its subsequent implementation. 
For the effective management of innovative technologies application, it is necessary to determine the role and place of innovation in the process of creation and its application. According to the data presented in Figure 3, the interaction of the scientific, industrial structure with universities within the framework of the functioning of the process of creating and applying innovative technologies will provide a significant increase in the quality of scientific achievements.

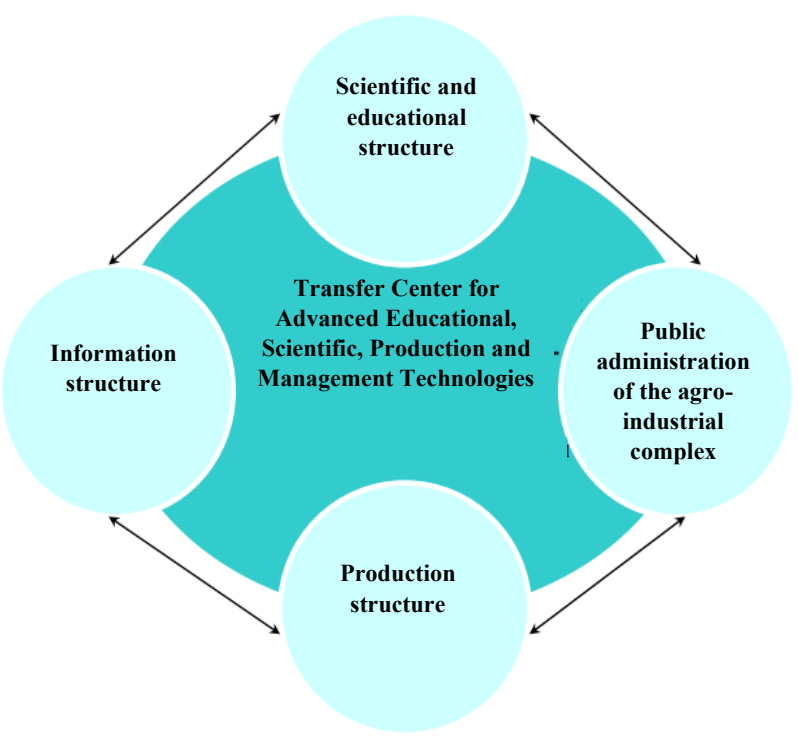

Fig. 2. Diagram of the relationship between the components of the process of creating and applying innovative technologies

It will also contribute to the development of infrastructure for the implementation of innovative projects and create preconditions for the optimal development of the system of existing innovations. 


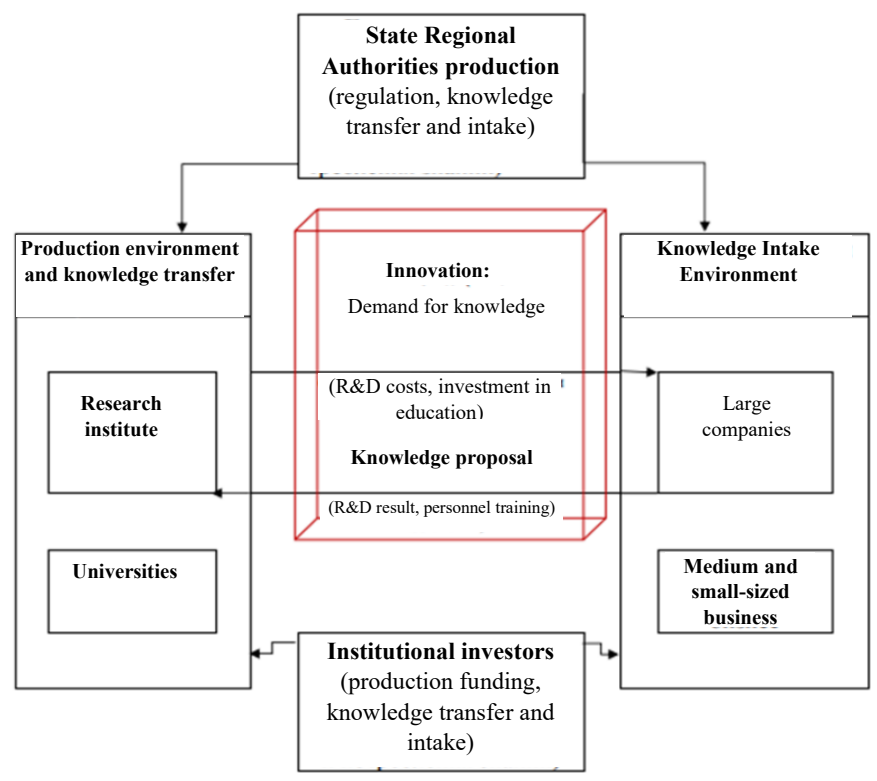

Fig. 3. The role and place of innovation in the process of creating and applying innovative technologies

Investors at the first stage are the state and specialized development funds. Further, at the second stage, the financing of proven technologies is carried out by customers on the basis of contracts concluded with universities and research institutes. The presented scheme is beneficial for agricultural enterprises seeking to modernize production.

\section{Conclusions}

As a result of the conducted research, we came to the conclusion that the use of innovative techniques and technologies, in modern conditions, has a high level of importance for the effective development of agriculture, as well as for increasing the competitiveness of agricultural products.

The identified problems, in our opinion, can be solved through public private partnerships in the creation and application of innovations in agriculture. It is under such conditions the effective intersection of science, government funding and agricultural production enterprises can be achieved.

\section{References}

1. V.I. Gaiduk, M.D. Kovalchuk, A. A. Ermakov, S.Y. Kamysheva. Revista Inclusiones, T. 7. No. S2-3, 188 (2020)

2. A.N. Bugara, http://apej.ru (2016)

3. I.O. Vlasova, Exploration Survey Company, 1(57), 207 (2016)

4. E.A. Egorov, Zh.A. Shadrina, G.A. Kochian Gardening and viticulture, 3, 5 (2016)

5. M.D. Kovalchuk, "Green Economy" in the Agro-Industrial Complex: Challenges and Development Prospects. Materials of the All-Russian Scientific Conference, 243 (2018) 
6. M.D. Kovalchuk, E.A. Shibanikhin, Materials of the international scientific conference, 152 (2017)

7. A.I. Trubilin, Justification of directions and assessment of the effectiveness of innovative development of import-substituting industries in the Krasnodar Territory, 150 (2019)

8. A.I. Trubilin., V.P. Chaika, A.I. Papakhchyan, A.V. Tolmachev, International Agricultural Journal, 2 (368), 22 (2019) 